\title{
Surgical treatment of esotropia and unilateral ptosis in a patient with Cornelia de Lange syndrome
}

\author{
Won Jae Kim \\ Department of Ophthalmology, Yeungnam University College of Medicine, Daegu, Korea
}

Received: March 30, 2018

Revised: April 17, 2018

Accepted: May 10, 2018

Corresponding author:

Won Jae Kim

Department of Ophthalmology,

Yeungnam University College of

Medicine, 170, Hyeonchung-ro,

Nam-gu, Daegu 42415, Korea

Tel: +82-53-620-4119

Fax: +82-53-626-5936

E-mail: eyekwj@ynu.ac.kr
Cornelia de Lange syndrome (CdLS) is a rare multisystemic disorder that is characterized by mental retardation, prenatal and postnatal growth retardation, limb anomalies, and distinctive facial features, which include arched eyebrows that often meet in the middle (synophrys), long eyelashes, low-set ears, small and widely spaced teeth, and a small and upturned nose. Ophthalmic manifestations include long eyelashes, nasolacrimal duct obstruction, myopia, ptosis, and strabismus. There has been no report of surgical treatment for esotropia and unilateral ptosis in patients with CdLS in Korea. I report a patient with CdLS who underwent surgical treatment for esotropia and unilateral ptosis with a good surgical outcome.

Keywords: Cornelia de Lange Syndrome; Strabismus; Ptosis; Surgery

\section{Introduction}

Cornelia de Lange syndrome (CdLS) is a rare multisystemic disorder that is characterized by mental retardation, prenatal and postnatal growth retardation, limb anomalies, and distinctive facial features, which include arched eyebrows that often meet in the middle (synophrys), long eyelashes, low-set ears, small and widely spaced teeth, and a small and upturned nose [1-3]. The clinical features vary widely among affected individuals and range from relatively mild to severe. Ophthalmic manifestations include long eyelashes, nasolacrimal duct obstruction, myopia, ptosis, and strabismus $[4,5]$. There has been no report of surgical treatment for esotropia and unilateral ptosis in patients with CdLS in Korea. I report a patient with CdLS who underwent surgical treatment for esotropia and unilateral ptosis with a good surgical outcome.

\section{Case}

Informed consent was obtained from the patient's parent. A 5-year-old girl was referred to our ophthalmology department for surgical treatment of esotropia and unilateral ptosis of the right eye. She had been previously diagnosed with CdLS at another clinic and had undergone regular follow-up. She had been born at 36 weeks of gestation with a birth weight of $1,900 \mathrm{~g}$. She had the typical facial features of CdLS, psychomotor delay, and intellectual disability (Fig. 1). We were unable to measure the visual acuity due to poor cooperation. The fixation of the right eye was weaker compared with that of the left eye. She also had ptosis, which covered the visual axis of the right eye. The extraocular examination showed 50 prism diopters of esotropia with abduction limitation of the right eye (Fig. 2A). Nystagmus was not observed. The refractive errors were -0.50 diopters (D) in both eyes. The fundus examination revealed peripapillary pigmentation of the right eye and a normal appearance of the left eye. The forced duction test was performed under general anesthesia; it did not reveal any restriction of the medial rectus in the right eye. Exploration showed that the lateral rectus muscle had a normal appearance, and it did not have any restriction.

Copyright@ 2019 Yeungnam University College of Medicine

This is an Open Access article distributed under the terms of the Creative Commons Attribution Non-Commercial License (http://creativecommons.org/licenses/by-nc/4.0/) which permits unrestricted non-commercial use, distribution, and reproduction in any medium, provided the original work is properly cited. 

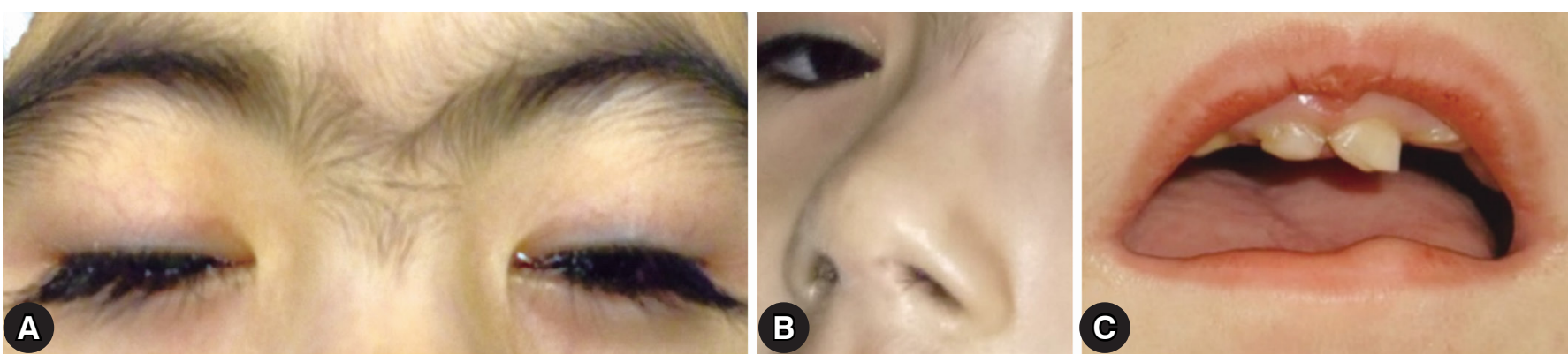

Fig. 1. Image of the patient with Cornelia de Lange syndrome demonstrating long eyelashes and arched eyebrows that meet in the middle (synophrys, A), small and upturned nose (B), and small and widely spaced teeth (C).
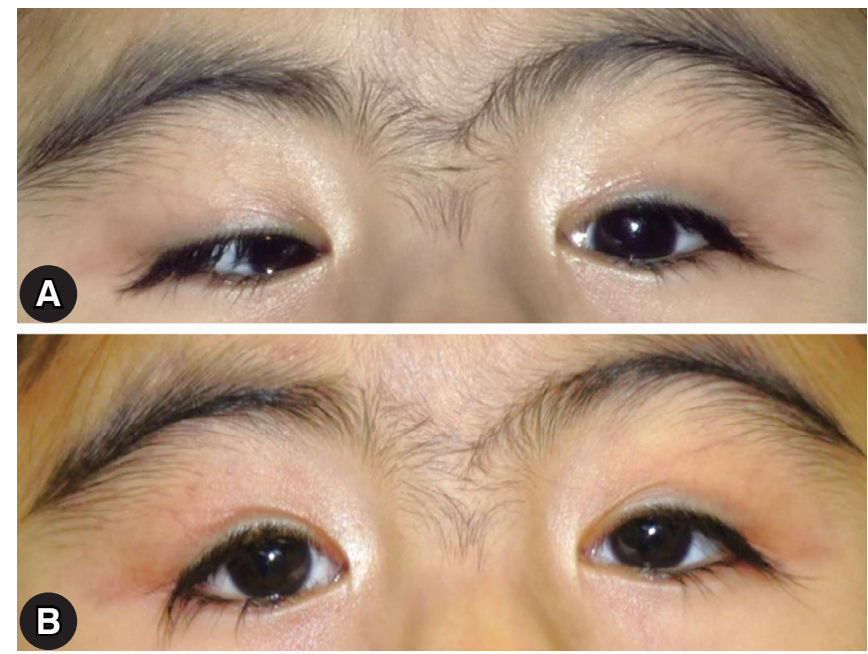

Fig. 2. Preoperative image of the patient demonstrating esotropia and ptosis covering the visual axis of the right eye (A). Four months after surgical treatment, the patient had stable ocular alignment with good eyelid position (B).

A 7-mm resection of the lateral rectus and 6-mm recession of the medial rectus were performed on the right eye without augmentation. The frontalis sling procedure was performed for the treatment of right ptosis. Four months later, the patient had stable ocular alignment with good eyelid position (Fig. 2B).

\section{Discussion}

CdLS occurs sporadically in most patients $[2,5]$. The exact etiology of CdLS is still unknown, but five genes have been reported to be associated with CdLS; the mutations of these genes comprise the underlying defect in $70 \%$ of the patients $[2,6]$. The initial diagnosis of CdLS is based on the clinical features, with specific signs, symptoms, and developmental characteristics forming the main criteria. Clinical diagnostic criteria have been proposed and include long eyelashes, ptosis, tear duct malformation or blepharitis, myopia $\geq-6.00 \mathrm{D}$, and a major eye malformation or peripapillary pigmentation as ophthalmic features [2]. Therefore, an ophthalmic examination can be helpful in the diagnosis of CdLS in an atypical case. In the present case, the patient had large-angle esotropia and severe unilateral ptosis. Compared with strabismus, ptosis is a relatively common clinical feature. Wygnanski-Jaffe et al. have reported the ophthalmic features in 120 patients with CdLS [7]. In their largest series, $10 \%$ of patients $(11 / 113)$ had esotropia and $44 \%$ of patients $(41 / 117)$ had varying degrees of ptosis, ranging from mild cosmetic changes to functional obstruction of the visual axis. Nallasamy et al. have evaluated the genotype-phenotype correlation with regard to the severity of ophthalmic findings in patients who had been previously screened for mutations in the Nipped-B-like gene [5]. In their study, nearly one-half of the included patients (25/54) had ptosis, and its severity was increased in patients who had truncating mutations compared to those who had missense mutations. Only 2 of the 15 patients with strabismus required surgical treatment. Because patients with CdLS have short horizontal palpebral fissures [7], it is sometimes difficult to get a clear surgical field during strabismus surgery, especially during medial rectus muscle surgery. A surgeon should take these into consideration during surgical planning.

Patients with CdLS have many ophthalmic problems, such as ptosis, strabismus, refractive errors, and nasolacrimal duct obstruction $[5,7,8]$. The treatment strategy should be based on each patient's symptoms. The surgical correction of ptosis and strabismus can improve the quality of the life of an affected patient. This report should help surgeons to consider surgical treatment of ptosis and strabismus in patients with CdLS.

\section{Conflicts of interest}

No potential conflicts of interest relevant to this article was reported. 


\section{Patient consent}

Patient's guardians provided written consent for the use of her images.

\section{ORCID}

Won Jae Kim, https://orcid.org/0000-0001-8869-0349

\section{References}

1. Levin AV, Seidman DJ, Nelson LB, Jackson LG. Ophthalmologic findings in the Cornelia de Lange syndrome. J Pediatr Ophthalmol Strabismus 1990;27:94-102.

2. Boyle MI, Jespersgaard C, Brøndum-Nielsen K, Bisgaard AM, Tümer Z. Cornelia de Lange syndrome. Clin Genet 2015;88:112.

3. Kline AD, Krantz ID, Sommer A, Kliewer M, Jackson LG, FitzPatrick DR, et al. Cornelia de Lange syndrome: clinical review, diagnostic and scoring systems, and anticipatory guidance. Am J Med Genet A 2007;143A:1287-96.

4. Kim IT, Park JW, Choi WC. A Korean case of Cornelia de Lange syndrome. Korean J Ophthalmol 2005;19:153-5.

5. Nallasamy S, Kherani F, Yaeger D, McCallum J, Kaur M, Devoto $\mathrm{M}$, et al. Ophthalmologic findings in Cornelia de Lange syndrome: a genotype-phenotype correlation study. Arch Ophthalmol 2006;124:552-7.

6. Park KH, Lee ST, Ki CS, Byun SY. Cornelia de Lange Syndrome with NIPBL gene mutation: a case report. J Korean Med Sci 2010;25:1821-3.

7. Wygnanski-Jaffe T, Shin J, Perruzza E, Abdolell M, Jackson LG, Levin AV. Ophthalmologic findings in the Cornelia de Lange Syndrome. J AAPOS 2005;9:407-15.

8. Stacey AW, Sparagna C, Borri M, Rizzo S, Hadjistilianou T. A 6-year-old boy with Cornelia de Lange syndrome and Coats disease: case report and review of the literature. J AAPOS 2015;19:474-8. 